\title{
Introduction to the special issue on regional development and mobility in the European Union
}

\author{
Peter Huber $\cdot$ Klaus Nowotny
}

Published online: 25 September 2012

(C) Springer Science+Business Media New York 2012

Not only since its last two rounds of enlargement in 2004 and 2007, but also before, the European Union has faced major cohesion problems, manifesting themselves in substantial income and unemployment differences between countries and regions in the EU. These are currently highlighted in the public policy debate on the markedly different economic developments of Northern and Southern European countries which have contributed to the EU's current economic and financial crisis. At the same time Europe's regions face increased globalization, rapid structural change and markedly different productivity developments, all of which challenge the EU's cohesion policy.

This special issue of Empirica brings together a series of papers that were presented at two workshops (the 4th WIFO Regional Economics Workshop on Regional Development and Mobility in the European Union organized by the Austrian Institute of Economic Research in Vienna and the 8th EU Real meeting organized by the Centre For North South Economic Research-CRENOS—in Porto Conte, Sassari) in September 2011. The aims of these workshops were to discuss and analyze the regional effects of European integration and future challenges for regional policy. Accordingly the papers presented focus on the effects of migration, foreign direct investments, technological progress and structural change on different aspects of regional development both from the perspective of the EU as a whole as well as from the perspective of individual member countries.

Two of the papers considered deal with migration. Huber and Tondl notice the rapid increase in East-West migration that has marked much of the last decade in the EU. They suggest that at least according to economic theory this increase in

P. Huber $(\square) \cdot$ K. Nowotny

Austrian Institute for Economic Research (WIFO), Arsenal, Objekt 20, 1030, Wien, Vienna, Austria e-mail: Huber@wifo.ac.at

K. Nowotny

University of Salzburg, Residenzplatz 9, 5010 Salzburg, Austria

e-mail: Klaus.Nowotny@sbg.ac.at 
mobility-aside from having potentially adverse effects on regional labor markets-could also have contributed to more rapid productivity and GDP per capita convergence among European regions. Using a data set covering the NUTS 2 regions of $25 \mathrm{EU}$ countries covering the period from 2000 to 2007 the authors find that net migration has an insignificant impact on regional unemployment rates but a small positive impact on both GDP per capita and labor productivity. Furthermore, they also find that this effect is mainly due to migrants from abroad and is symmetric in emigration and immigration regions. Since most emigration regions have low GDP per capita and productivity while immigration regions have high GDP per capita and productivity, this leads the authors to conclude that migration represents a transfer of human capital from poor to rich regions and that migration thus has a modestly negative impact on convergence.

Brunow and Brenzel, by contrast, approach the issue of migration from a slightly different angle. Their starting point is that increased migration in the last decades has also led to increased cultural diversity in many regions, as migrants from different cultural backgrounds are moving to the EU. From the theoretical point of view this could have positive or negative impacts on regional income since on the one hand increased diversity, through knowledge spillovers between different groups, could help to increase productivity in the region, while on the other hand the increased costs of coordinating a more heterogeneous labor force that are implied by increased diversity could also reduce productivity. Like Huber and Tondl, Brunow and Brenzel also find that an increased share of foreign born in a region increases GDP after controlling for other relevant influences and instrumenting appropriately for migration.

Their results, which are also based on EU-wide data, however, also indicate that cultural diversity has positive net effects over and above that of migration. Furthermore this positive effect seems to be largest when there are only one or few dominant groups among the foreign born in a region. This leads the authors to conclude that immigration may be seen as a promising way to countervail potential labor shortages due to demographic ageing in the European regions, in particular when regions attract migrants only from few ethnicities.

While these two contributions are closely related, the contribution by Gauselmann and Marek shifts focus to foreign direct investments. In particular they are interested in the impact of agglomeration and labor market factors on the choice of location of MNE's. Based on a micro-data set on foreign direct investments in Eastern Germany, the Czech Republic and Poland the authors confirm many of the results of the literature for mature market economies. They suggest that FDIs prefer to locate in regions with a high specialization in the sector of the investing enterprises and a potential for knowledge spillovers. In addition-and in contrast to earlier literature on Central and Eastern European countries-they also find that high wages may not deter FDIs if they are accompanied by offsetting factors such as a high level of human capital or high productivity. This leads the authors to conclude that FDIs in the post transition economies analyzed here are no longer mainly driven by efficiency seeking behavior of firms, but also by access to knowledge resources and highly qualified labor. In this sense the new member states that joined the EU in 2004 seem to have converged to the patterns found in the pre2004 member states. 
The contribution of Ladu, by contrast, uses NUTS 2 level data from 10 EU countries to analyze the relationship between total factor productivity growth and employment. As shown by previous work this relationship could be either positive-if higher productivity growth induces firms to become more profitable and therefore to create more jobs-or negative-if technological progress resulting in TFP growth causes some firms to become obsolete. In contrast to previous empirical examinations, which find a positive impact of total factor productivity growth on employment in the long run, Ladu finds that higher total factor productivity growth reduces employment both in the short and in the long run. She hypothesizes that these differences in results could be due to the different level of aggregation (regional rather than national) used in her paper. If firms hire from workers from all regions, while job destruction impacts only on the local labor market, regional analysis would tend to find more negative impacts of productivity growth on employment than analyses at the national level, as performed in previous research.

Finally, Basile, Girardi, Mantuuano and Pastore present a case study on the impact of economic structure and structural change in Italy. They use detailed regional data constructed according to economic definitions of regions and sophisticated spatial econometric techniques to analyze the relationship between sector specialization, structural change and unemployment in Italy. This is a particularly interesting case study because of the substantial structural change that southern Italian regions have experienced in the period analyzed (2004 to 2008) and because of the importance structural change-or lack thereof-has received in the current debate on re-establishing competitiveness in the southern European periphery.

They find that sector shifts and the degree of specialization of a region impact negatively on regional unemployment, while diversified regions show a better labor market performance. Furthermore their results also indicate that regions that are located in an industrial district perform better than regions that are not. This therefore suggests a need for appropriate structural policies in peripheral regions of the EU to (re-)establish their competitiveness. 